\title{
Qualitative Analysis of Alfalfa Seed Methanol Extract by GC-MS and Determination of Antioxidant Properties
}

\author{
Hafize Dilek Tepe* \\ Manisa Celal Bayar University, Applied Science Research Center, Manisa, Turkey \\ *hafize.dilek@hotmail.com \\ Received: 06 December 2018 \\ Accepted: 11 June 2019 \\ DOI: $10.18466 /$ cbayarfbe.493017
}

\begin{abstract}
Alfalfa plant has a great importance for agriculture in Turkey and throughout the world. Antioxidant activities (DPPH and NO scavenging effects) have been studied from the methanol extraction of the seeds, and organic volatile molecule contents have been analyzed by GC-MS. Physical and chemical analysis of the seed were also carried out to elucidate the structure. As a result of the experiments, a concentration-dependent increase was observed in DPPH and NO scavenging (\%) activities from the 0.5, 1 and $2 \mathrm{mg} / \mathrm{ml}$ methanol extract concentrations of alfalfa seeds. In GC-MS analysis, it was found that squalene, a pharmacologically active molecule, is present in alfalfa seeds. As a result of chemical and physical analyzes, it was determined that the crude protein content is $33.79 \%$ and crude oil is $8.11 \%$. Although alfalfa is widely used in agriculture and as animal bait, this study shows that alfalfa seeds are also pharmacologically crucial for containing rich molecules.
\end{abstract}

Keywords: Clover, squalene, DPPH, NO, scavenging activity.

\section{Introduction}

Clover (Medicago sativa L.) is a perennial, flowering plant from the pea family that can grow in various climatic conditions. The clover plant known in the world as alfalfa and it is one of the most renowned medicinal plants, with bluish-colored flowers, about one meter in length and with steep green leaves [1]. Alfalfa plants are beneficial for both humans and animals. People use alfalfa's sprouts, sensitive roots and dried leaves (which can be used as a dietary supplement in forms such as tablets, powders and tea), animals use the form of hay and feed. Leaves and stems are rich in minerals, proteins and vitamins. The medicinal uses of this plant are as follows: a restorative tonic, antifungal agent for digestion, as well as a food that promotes milk secretion in nursing mothers. Alfalfa is also used as a long-term ayurvedic and homoeopathic drug in central nervous system disorders. Antioxidant, antiinflammatory and antidiabetic effects of the plant have been reported [2-4].

Nowadays, alfalfa is the world's largest feed produced legumes as feed. In 2009, it was grown in an area of 30 million hectares worldwide. Of this, 11.9 million hectares were planted in North America, 7 million hectares in South America, 7.12 million hectares in Europe, 2.23 million hectares in Asia, 1.75 million hectares in Africa and Oceania [5]. According to the data of 2016 in Turkey, about 630.000 hectares of alfalfa were planted and 9.5 million tons of dry grasses were produced [6].
Antioxidants are micronutrients that can prevent oxidative damage caused by free radicals. Many medicinal plants are rich in antioxidant compounds [3, 4]. To date, many plants have been studied as natural antioxidant sources and various compounds (many of which are polyphenols) have been isolated from these plants. Low and high molecular weight polyphenolic compounds with antioxidant properties were investigated and proposed against lipid peroxidation. Antioxidants are also widely used to prevent degradation of other oxidizable products such as cosmetics, drugs and plastics [7, 8]. Alfalfa contains essential amino acids such as, valine, leucine, threonine and lysine. Due to these essential amino acids and their amount alfalfa is similar to egg white. Green shoots at the top of the plant contain plenty of chlorophyll and various vitamins. These are $\mathrm{C}, \mathrm{E}, \mathrm{B} 1, \mathrm{~B} 2, \mathrm{~B} 6, \mathrm{~B} 12$, niacin, folic acid, biotin, inositol, choline and $\beta$ carotene. It also contains valuable minerals such as $\mathrm{Ca}$, $\mathrm{Cu}, \mathrm{Fe}, \mathrm{Mg}, \mathrm{Mn}, \mathrm{P}, \mathrm{Zn}, \mathrm{Si}$ [2]. Recent studies have found lithium of $1.12 \mathrm{mg} / \mathrm{g}$ in the alfalfa plant growing in the Oman desert [9]. The lithium element is an emotional state regulator and is known to be used in the treatment of bipolar disorders [10]. In terms of proteins and vitamins alfalfa leaf extract has been recognized by the European Food Safety Authority (EFSA) as a rich dietary supplement. Many studies have shown that alfalfa is rich in biologically active compounds as well as nutritional properties [11]. 


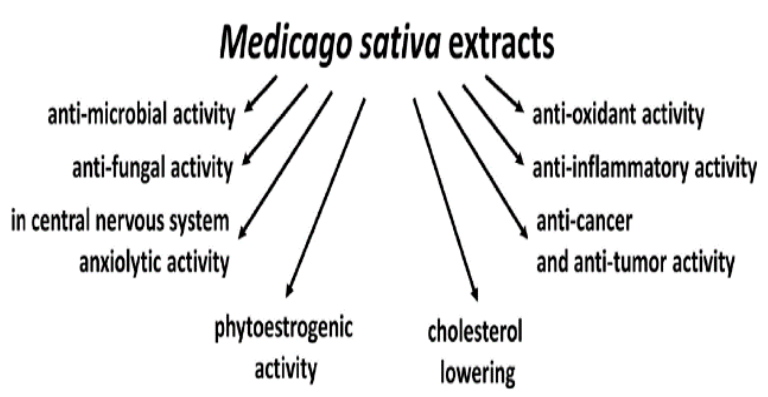

Figure 1. Pharmacological and biological activity of $M$. sativa L. extracts. [12].

Studies to date, the roots, stems and leaves of the alfalfa plant were used as material. There is no sufficient amount of work with the seed part of the plant. In this study we used the seeds of alfalfa plant. Although alfalfa planting is very common in Turkey, properties of its seed has not been widely studied. In this study, methanol extract of alfalfa seeds was prepared and qualitative analysis of gas chromatography / mass spectrometry (GC-MS) was performed from the methanol extract. In this way, organic volatile molecules of the plant seeds were identified. Besides, 1,1 -diphenyl-2-picrylhydrazyl (DPPH) and nitric oxide (NO) free radical scavenging activities were also analyzed in order to elucidate the antioxidant capacity and various chemical and physical analyzes were carried out to reveal the alfalfa seed structure.

\section{Material and Method}

\subsection{Extraction Process}

Alfalfa seeds were obtained from a local market in Izmir, Turkey. Before the extraction process, alfalfa seeds were washed in pure water and dried in an oven at $80{ }^{\circ} \mathrm{C}$. For analysis, the seeds were pulverized in highspeed plant mill and prepared for extraction. $2 \mathrm{~g}$ of powdered seed samples were extracted in $40 \mathrm{ml}$ of $80 \%$ methanol in ultrasonic bath for 30 minutes then left at room temperature. The final extraction concentrate was then adjusted to $50 \mathrm{mg} / \mathrm{ml}$. DPPH and NO scavenging activities in percentage and GC-MS analyzes were determined using this extraction.

\subsection{DPPH and NO scavenging Activity}

The antioxidant activities of the extracts were tested using the DPPH radical with minor modifications [13]. $2.10^{-4} \mathrm{M}$ DPPH solution was prepared in methanol for this method. $0.5 \mathrm{ml}$ was taken from each sample and on $4 \mathrm{ml}$ of DPPH solution was added. The mixture was shaken and kept at room temperature for 60 minutes in the dark. $80 \%$ methanol was used as a blind and samples were read at $517 \mathrm{~nm}$ by spectrophotometer (TECAN Infinite M200 microplate reader). The results were calculated according to the following equation.
DPPH scavenging activity \%

$=\left(1-\right.$ Abs sample $_{\text {s }} / \mathrm{Abs}$ blind $) \times 100$

Nitric oxide scavenging activity was determined according to the following method [14]. Four ml each of the extracts prepared in different concentrations were taken and $1 \mathrm{ml}$ of sodium nitroprusside solution (25 $\mathrm{mM}$ ) was added to the mixture and incubated for 2 hours at $37^{\circ} \mathrm{C}$. After incubation, $0.5 \mathrm{ml}$ of the solutions were removed and mixed with $0.3 \mathrm{ml}$ of Griess reagent $\left(5 \% \mathrm{H}_{3} \mathrm{PO}_{4}\right.$ in $1 \%$ sulfanilamide and $0.1 \%$ naphthylethylenediamine dihydrochloride). The absorbance of the formed chromophore was read against the blind at $570 \mathrm{~nm}$ on the spectrophotometer (TECAN Infinite M200 Microplate reader). The results were calculated

NO scavenging activity $\%=$

(Abs blind $-\mathrm{A}_{\mathrm{s} \text { ample }} / \mathrm{Abs}$ blind $) \times 100$

\subsection{GC / MS Organic Molecule Determination}

Volatile molecules in the extract were qualitatively analyzed in electron ionization (EI) mode with Agilent Technology 7890A Gas Chromatography (GC) Mass spectrometer (MS). Chromatographic column Agilent HP-5MS, capillary column $(30 \mathrm{~m} * 0.25 \mathrm{~mm}$, film thickness of $0.25 \mathrm{~mm}$ ). The furnace temperature was started at $40{ }^{\circ} \mathrm{C}$, followed by standing for 5 minutes, then at $5{ }^{\circ} \mathrm{C}$. $\mathrm{min}^{-1}$ at $280{ }^{\circ} \mathrm{C}$. and held for $5 \mathrm{~min}$. Helium gas $(99.999 \%)$ was used as the carrier gas. The constant flow rate is $1.5 \mathrm{ml} \mathrm{min}^{-1}$ and the injector temperature is $250{ }^{0} \mathrm{C}$. The extract was injected in splitless mode with $1 \mathrm{ml}$. Interpretation of the mass spectrum was performed according to the National Institute of Standards and Technology (NIST) database.

\subsection{Other physical and chemical analyzes}

Humidity, dry matter, crude protein, crude cellulose, crude oil and ash were analyzed for alfalfa seeds. Kjeldahl method was used in Gerhardt Vapodest 45s device for protein content and Gerhardt fibretherm cellulose device was used for cellulose content. Humidity was determined at $100{ }^{\circ} \mathrm{C}$ in the Memmert etuv. Carbolite ash furnace was used at 600 ${ }^{\circ} \mathrm{C}$ for ash content. Crude oil content was performed by using Gerhardt soxtherm device.

\section{Results and Discussion \\ 3.1. DPPH and NO scavenging Activity}

In the study, DPPH scavenging activity in percentage increased by $4.47 \%$ at extract concentration of 0.5 $\mathrm{mg} / \mathrm{ml}$, and extract concentrations of 1 and $2 \mathrm{mg} / \mathrm{ml}$ compared to control group increases of $11.05 \%$ and $18.30 \%$ respectively. As the extract concentration increased, the DPPH radical scavenging capacity was also increased (Figure 2). 


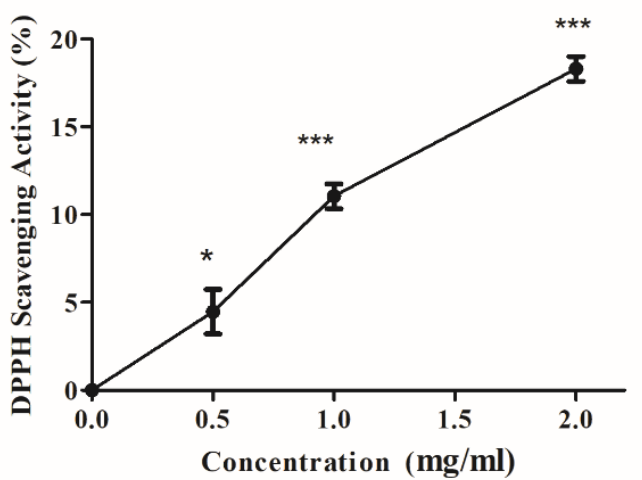

Figure 2. DPPH scavenging activity (\%) in alfalfa seed methanol extract $(\mathrm{n}=3, \mathrm{P}<0.05)$.

Nitric oxide scavenging activities (\%) according to the control group; an increase of $37.15 \%$ in the amount of $0.5 \mathrm{mg} / \mathrm{ml}$ extract, for the concentrations of 1 and 2 $\mathrm{mg} / \mathrm{ml}$ extracts, NO scavenging levels were increased by $63.67 \%$ and $91.82 \%$, respectively. The increase in extract concentration also increased NO inhibition in the medium (Figure 3).

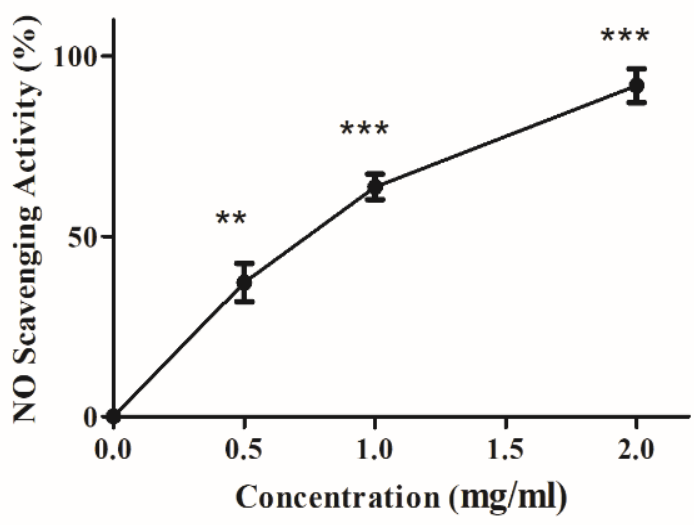

Figure 3. NO scavenging activity (\%) in alfalfa seed methanol extract. $(\mathrm{n}=3, \mathrm{P}<0.05)$.

Alfalfa leaf proteins in a study, a high rate of DPPH radical scavenging activity was also found as the sample concentration increased. Thus, it can be said that alfalfa leaf proteins have a good antioxidant properties and have high DPPH radial scavenging activity [15].

\subsection{GC-MS Organic Molecules Determination}

Table 1. Results of GC-MS analysis of methanol extract in alfalfa seeds.

\begin{tabular}{lll} 
Line & $\mathbf{R t}$ & Molecule Name \\
$\mathbf{1}$ & 5.599 & Hexanal \\
$\mathbf{2}$ & 6.609 & N-Methylcarbamic Acid Ethyl Ester \\
$\mathbf{3}$ & 10.036 & 3-Butenamide \\
$\mathbf{4}$ & 12.112 & 3-hydroxybutyric acid \\
$\mathbf{5}$ & 13.743 & Erythritol \\
$\mathbf{6}$ & 16.501 & 1-Dodecene \\
$\mathbf{7}$ & 20,128 & 2-Methoxy-4-vinylphenol; \\
$\mathbf{8}$ & 21.959 & 1-Tetradecene \\
$\mathbf{9}$ & 22.774 & (-)-beta-caryophyllene \\
$\mathbf{1 0}$ & 24.099 & Xanthosine \\
$\mathbf{1 1}$ & 24.776 & 3-Methyl-Thiophene-2-Carboxamide \\
$\mathbf{1 2}$ & 25.045 & Phenol, 2,4-bis(1,1-dimethylethyl) \\
$\mathbf{1 3}$ & 26.371 & 2,6-dimethyl-3-(methoxymethyl)-p-benzoquinone \\
$\mathbf{1 4}$ & 26.796 & (-)-Caryophyllene oxide \\
$\mathbf{1 5}$ & 26.841 & 1-heptadecene \\
$\mathbf{1 6}$ & 27.746 & Megastigmatrienone \\
$\mathbf{1 7}$ & 31.243 & Trichloroacetic acid,pentadecyl ester \\
$\mathbf{1 8}$ & 31.385 & Octadecane \\
$\mathbf{1 9}$ & 32.343 & Phytone \\
$\mathbf{1 0}$ & & \\
\hline
\end{tabular}

\section{Similarity \% Molecular Weight (g/mol)}

\begin{tabular}{ll}
64 & 100.15 \\
43 & 103.12 \\
46 & 85.104 \\
50 & 104.105 \\
50 & 122.120 \\
95 & 168.31 \\
52 & 150.174 \\
96 & 196.37 \\
96 & 204.351 \\
50 & 284.225 \\
64 & 141.191 \\
89 & 206.324 \\
78 & 180.200 \\
81 & 220.350 \\
95 & 238.452 \\
91 & 190.281 \\
92 & 373.786 \\
70 & 254.494 \\
83 & 268.478 \\
\hline
\end{tabular}


Celal Bayar University Journal of Science

Volume 15, Issue 2, 2019, p 175-180

Doi: $10.18466 /$ cbayarfbe.493017

H. Dilek Tepe

\begin{tabular}{|c|c|c|c|c|}
\hline 20 & 32.868 & 1,2-benzenedicarboxylic acid,butyl 2-methylpropyl ester & 86 & 278.343 \\
\hline 21 & 33.413 & Decane,3,6-dimethyl & 83 & 170.335 \\
\hline 22 & 33.957 & Hexadecanoic acid, methyl ester & 99 & 270.451 \\
\hline 23 & 34.814 & n-Hexadecanoic acid & 99 & 256.424 \\
\hline 24 & 35.182 & Estra-1,3,5(10)-trien-17.beta.-ol & 87 & 256.382 \\
\hline 25 & 35.445 & Eicosane & 86 & 282.547 \\
\hline 26 & 35.884 & Palmitic acid & 80 & 256.424 \\
\hline 27 & 36.979 & Patchulane & 62 & 206.366 \\
\hline 28 & 37.151 & 9,12-octadecadienoic acid methyl ester & 99 & 294.472 \\
\hline 29 & 36.360 & methyl oleate & 60 & 296.488 \\
\hline 30 & 37.487 & 4,7-Epoxy-1H-inden-5-ol,1-butyl-2-ethyloctahydro & 96 & 238.366 \\
\hline 31 & 36.473 & Oleic Acid & 90 & 282.461 \\
\hline 32 & 38.986 & Cyclopentadecanone, 2-hydroxy- & 90 & 240.382 \\
\hline 33 & 39.309 & (Z)-9,17-octadecadienal & 86 & 264.446 \\
\hline 34 & 39.461 & 1-Oxaspiro[2.5]octane, 5,5-dimethyl-4-(3-methyl-1,3-butadienyl)- & 93 & 206.16 \\
\hline 35 & 40.033 & 9,12-Octadecadienoic acid (Z,Z)- & 91 & 280.445 \\
\hline 36 & 40.128 & 2-Methyl-Z,Z-3,13-octadecadienol & 81 & 280.496 \\
\hline 37 & 40.759 & 7-Pentadecyne & 93 & 208.389 \\
\hline 38 & 41.077 & 12-Methyl-E,E-2,13-octadecadien-1- ol & 90 & 280.276 \\
\hline 39 & 41.636 & Hexanoic acid, 2-hexenyl ester, & 80 & 198.302 \\
\hline 40 & 41.810 & 9-Octadecenamide, $(\mathrm{Z})$ - & 99 & 281.477 \\
\hline 41 & 42.226 & 1,E-11,Z-13-Heptadecatriene & 55 & 234.420 \\
\hline 42 & 42.314 & 7,11-Hexadecadienal & 95 & 236.393 \\
\hline 43 & 42.878 & Diepicedrene-1-oxide & 90 & 220.356 \\
\hline 44 & 43.706 & 7-Isopropyl-4a-methyloctahydro-2(1H)-naphthalenone & 93 & 208.340 \\
\hline 45 & 44.987 & 1,2-Benzisothiazole, 3-(hexahydro-1H-azepin-1-yl)-, 1,1-dioxide & 93 & 264.34 \\
\hline 46 & 45.981 & Oleic acid, propyl ester & 55 & 324.541 \\
\hline 47 & 46.085 & 2,5-Furandione,3-dodecyl & 62 & 266.376 \\
\hline 48 & 46.932 & 13-Tetradecen-1-ol acetate & 90 & 254.414 \\
\hline 49 & 46.980 & 9,15-Octadecadienoic acid, methyl ester, (Z,Z) & 90 & 294.472 \\
\hline 50 & 48.082 & 1-Hexacosene & 58 & 364.691 \\
\hline 51 & 48.747 & Squalene & 99 & 410.718 \\
\hline 52 & 49.120 & $\begin{array}{l}\text { 2-Cyclopropyl-N-(1-cyclopropylethyl)-2-methylcyclopropane-1- } \\
\text { carboxamide }\end{array}$ & 83 & 207.317 \\
\hline 53 & 50.329 & $\begin{array}{l}\text { 2,2-Dimethyl-3-(3,7,16,20-tetramethyl-heneicosa-3,7,11,15,19- } \\
\text { pentaenyl)-oxirane }\end{array}$ & 92 & 412.370 \\
\hline 54 & $\mathbf{5 3 . 4 0 7}$ & Vitamin E & 99 & 430.706 \\
\hline
\end{tabular}

GC-MS analysis of alfalfa seed methanol extracts was carried out qualitatively. The results were compared with the library (NIST) of the device in the database
(Table 1). According to the results obtained in alfalfa seed content; hexadecanoic acid methyl ester, nHexadecanoic acid, 9,12-octadecadienoic acid methyl 
ester, 9-Octadecenamide, (Z)-, squalene, vitamin E, we observed that the molecules exist predominantly.

Squalene is a naturally occurring hydrocarbon. Sterol and hopanoids belong to the wide family of cyclic triterpenes. Squalene is an important intermediate in the biosynthesis of these molecules. Sterols and hopanoids are present in the structure of eukaryotic and prokaryotic organisms [16]. These molecules have critical biological functions such as the sequencing of lipids, membrane regulation [17]. Previous studies have shown that some plants accumulate high squalene. For example, the seeds of the Amaranth plant are now a major source of squalene. [18].

Squalene is a volatile organic compound, but its molecular weight is greater than that of other known volatile molecules such as monoterpenes, sesquiterpenes and green leaf volatiles. There are very few studies currently investigating large molecular weight volatile molecules. Therefore, there are not too many reports of isolation of squalene from plants. [19].

\subsection{Other physical and chemical analyzes}

According to the results, crude protein was found as $33.79 \mathrm{~g}$ and crude oil was $8.11 \mathrm{~g}$ in $100 \mathrm{~g}$ of alfalfa seed (Table 2). In a similar study on alfalfa seed, the seed was made into flour. Total protein, total lipid, ash and crude fiber contents in 100 grams of sample were reported as $34.24,1.39,11.65,21.38$ grams, respectively [20].

Table 2. Other physical and chemical analyzes.

\begin{tabular}{lc}
\hline Analysis & Amounts (\%) \\
\hline Humidity & 8.40 \\
Dry matter & 91.6 \\
Crude protein & 33.79 \\
Crude cellulose & 7.78 \\
Ash & 4.21 \\
Crude oil & 8.11
\end{tabular}

\section{Conclusion}

GC-MS analysis is the first step in understanding the nature of the active substances especially for the medicinal plants. Therefore, in this study, different volatile organic compounds were identified by GC-MS analysis from the methanol extract of alfalfa seeds along with antioxidant activities (DPPH and NO scavenging effects), physical and chemical analysis. This type of work will be useful for a detailed study in the future. Further research related to the pharmacological significance, diversity and detailed biochemistry of alfalfa will be able to add as new information in the traditional medical system.

\section{Author's Contributions}

Hafize Dilek Tepe: Drafted and wrote the manuscript, performed the experiment and result analysis.

\section{Ethics}

There are no ethical issues after the publication of this manuscript.

\section{References}

1. Bagavathiannan, MV, Van, ARC. 2009. The Biology and Ecology of Feral Alfalfa (Medicago sativa L.) and its implications for Novel Trait Confinement in North America. Critical Reviews in Plant Sciences; 28(1): 69-87.

2. Bora, KS, Sharma, A. 2011. Evaluation of Antioxidant and Cerebroprotective Effect of Medicago sativa Linn. against Ischemia and Reperfusion Insult. Evidence-Based Complementary and Alternative Medicine; 2011: 1-9.

3. Musa, EM, EL-Badwi, SM, Jah Elnabi, MA, Osman, EA, Dahab, MM. 2012. Hepatoprotective and toxicity assessment of Cannabis sativa seed oil in albino rat. International Journal of Chemical and Biochemical Sciences; 1: 69-76.

4. Younas, J, Hussain, F. 2014. In vitro Antidiabetic Evaluation of Allium sativum L. International Journal of Chemical and Biochemical Sciences; 5: 22-25.

5. Gaweł, E, Grzelak, M, Janyszek, M. 2017. Lucerne (Medicago sativa L.) in the human diet-case reports and short reports. Journal of Herbal Medicine; 10: 8-16.

6. TÜİK. 2016. Türkiye İstatistik Kurumu. http://www.tuik.gov.tr.

7. Abdallah, EM, Khalid, AE. 2012. A preliminary evaluation of the antibacterial effects of Commiphora molmol and Boswellia papyrifera oleo-gum resins vapor. International Journal of Chemical and Biochemical Sciences; 1: 1-5.

8. Hamid, AA, Aiyelaagbe, OO. 2012. Pharmacological investigation of Asystasia calyciana for its antibacterial and antifungal properties. International Journal of Chemical and Biochemical Sciences; 1: 99-104.

9. Hanif, MA, Al-Maskari, AY, Al-Sabahi, JN, Al-Hdhrami, I, Khan, MM, Al-Azkawi, A, Hussain, AI. 2015. Chemical characterisation of bioactive compounds in Medicago sativa growing in the desert of Oman. Natural Product Research; 29(24): 2332-2335.

10. Gray, JD, McEwen, BS. 2013. Lithium's role in neural plasticity and its implication for mood disorders. Acta Psychiatrica Scandinavica; $128(5): 347-361$.

11. Karimi, E, Oskoueian, E, Oskoueian, A, Omidvar, V, Hendra, R, Nazeran, H. 2013. Insight into the functional and medicinal properties of Medicago sativa (alfalfa) leaves extract. Journal of Medicinal Plants Research; 7(7): 290-297.

12. Rafinska, K, Pomastowski, $\mathrm{P}$, Wrona, $\mathrm{O}$, Górecki, $\mathrm{R}$, Buszewskbi, B. 2017. Medicago sativa as a source of secondary metabolites for agriculture and pharmaceutical industry. Phytochemistry Letters; 20: 520-539.

13. Zhang, GW, He, L, Hu, MM. 2011. optimized ultrasonic-assisted extraction of flavonoids from Prunella vulgaris L. and evaluation of antioxidant activities in vitro. Innovative Food Science \& Emerging; 12(1): 18-25.

14. Marcocci, I, Marguire, JJ, Droy-Lefaiz, MT, Packer, L. 1994. Thenitricoxide scavenging propertyof Ginkgo biloba extract. 
Biochemical and Biophysical Research Communications; 201: 748-755.

15. Xie, Z, Huang, J, Xu, X, Jin, Z. 2008. Antioxidant activity of peptides isolated from alfalfa leaf protein hydrolysate. Food Chemistry; 111: 370-376.

16. Do, R, Kiss, RS, Gaudet, D, Engert, JC. 2009. Squalene synthase: a critical enzyme in the cholesterol biosynthesis pathway. Clinical Genetics; 75: 19-29.

17. Goldstein, JL, DeBose-Boyd, RA, Brown, MS. 2006. Protein sensors for membrane sterols. Cell; 124: 35-46.

18. Jahaniaval, F, Kakuda, Y, Marcone, M.2000. Fatty acid and triacylglycerol compositions of seed oils of five Amaranthus accessions and their comparison to other oils. Journal of the American Oil Chemists' Society; 77: 847-852.

19. Vogler, U, Rott, AS, Gessler, C, Dorn, S. 2009. Terpene-mediated parasitoid host location behavior on transgenic and classically bred apple genotypes. Journal of Agricultural and Food Chemistry; 57: 6630-6635.

20. Apostol, L, Iorga, S, Mosoiu, C, Racovita, RC, Niculae, OM, Vlasceanu, G. 2017. Alfalfa concentrate a rich source of nutrients for use in food products. Journal of International Scientific Publications; 5: 66-73. 